Article

\title{
Fretting Wear Behavior and Photoelectron Spectroscopy (XPS) Analysis of a Ti/TiN Multilayer Film Deposited on Depleted Uranium
}

\author{
Shengfa $\mathrm{Zhu}{ }^{1}{ }^{(\mathbb{D})}$, Yanping $\mathrm{Wu}^{1, *}$, Zhengyang $\mathrm{Li}^{2}$, Liping Fang ${ }^{1}{ }^{\mathbb{C}}$, Anyi Yin ${ }^{1}$, Jiawei Yan ${ }^{1}$, \\ Fan Jiang ${ }^{1}$, Xiandong Meng ${ }^{1}$, Piheng Chen ${ }^{1, *}$ and Zhenbing Cai ${ }^{2, *}$ (1) \\ 1 Institute of Materials, China Academy of Engineering Physics, Mianyang 621900, China; \\ zhushf-306@163.com (S.Z.); fanglp26@163.com (L.F.); anyiyin@126.com (A.Y.); yanjiawei@caep.cn (J.Y.); \\ ywj-shan@163.com (F.J.); mengxiandong@caep.cn (X.M.) \\ 2 Tribology Research Institute, National Traction Power Laboratory, Southwest Jiaotong University, \\ Chengdu 610031, China; lzy_jiaoda@126.com \\ * Correspondence: Wuyanping-2@126.com (Y.W.); Chenph@live.cn (P.C.); Czb-jiaoda@126.com (Z.C.)
}

Received: 24 July 2018; Accepted: 21 August 2018; Published: 27 August 2018

\begin{abstract}
Depleted uranium has been widely applied in nuclear energy fields. However, its poor corrosion and wear resistance restrict its applications. A titanium/titanium nitride (Ti/TiN) multilayer film was deposited on a uranium surface to improve its fretting wear resistance. Fretting wear tests were carried out using a pin-on-disc configuration. The fretting behaviors of uranium and the Ti/TiN film were investigated under different normal loads. With the normal load increasing, the mode of fretting wear gradually transformed from slip region (SR) to mixed fretting region (MFR) and then to partial slip region (PSR). It is illustrated that the normal load had an obvious effect on the fretting wear behavior. The friction coefficients of both uranium and $\mathrm{Ti} / \mathrm{TiN}$ multilayer film decreased with the increase of the normal load. In SR, the main wear mechanisms were delamination and abrasion for uncoated uranium, and delamination and oxidation for uranium coated with the Ti/TiN multilayer film. Photoelectron spectroscopy (XPS) analysis also showed that the $\mathrm{Ti} / \mathrm{TiN}$ coating was oxidized and formed $\mathrm{TiO}_{2}$ during fretting wear. The wear depth of naked uranium was much greater than that of coated uranium, which demonstrated that the $\mathrm{Ti} / \mathrm{TiN}$ multilayer film could effectively improve the wear properties of uranium.
\end{abstract}

Keywords: depleted uranium; multilayer film; fretting wear; wear mechanism

\section{Introduction}

Depleted uranium (DU) has been widely applied in nuclear energy fields because of its unique nuclear properties. In order to satisfy specific engineering designs, uranium will inevitably be in contact or associated with other materials. The contact interface between uranium and the other material is proved to bear different stresses and relative clearances. During transport and service, uranium will be frequently affected by vibration, causing motion with small displacement amplitude [1,2]. Friction and fretting wear occur when two contacting parts are subjected to small-amplitude oscillatory sliding. Fretting damage can be divided into fretting fatigue, fretting wear, and fretting corrosion, which limit the lifetime of the components [3,4]. The wear debris of uranium are easily corroded in the presence of oxygen and water vapor, because of uranium high chemical reactivity, which presents severe environmental and health hazards [5-7].

Surface modification technique is an effective way to enhance the wear-resistant properties of industrial components and has been successfully used to improve the fretting wear resistance behaviors 
of different materials. Various methods have been used for this purpose, including the use of hard and soft metallic coatings, graphene oxide [8], $\mathrm{MoS}_{2}$ [9], nanocomposite coatings [10], and nanolayer coatings [11]. Different coatings have been tested to reduce friction and wear in various applications.

Titanium nitride (TiN) films have attracted much attention to improve the mechanical and tribological properties of materials, and in fact they have been widely applied in the field, for instance for cutting tools and parts of engine [12-19]. The fretting properties of TiN films in varying testing environments $[19,20]$ and at different temperatures $[13,16,18]$ and fretting parameters [12] have been studied. A Ti/TiN multilayer, because of good toughness and tribological behaviour, can significantly improve the wear resistance of the Ti-811 alloy [21]. However, there are few studies on the fretting wear resistance of uranium. The ion-plating technology has attracted tremendous attention due to its low deposition temperature, high deposition rate, and high adhesion strength. It is significant to study the fretting behavior of uranium and a Ti/TiN multilayer film prepared by the arc-ion-plating technology.

In this study, a Ti/TiN multilayer film was prepared on a uranium sample surface by the ion-plating technology. Fretting wear tests were carried out on uranium (indicated as U) and the Ti/TiN multilayer film (indicated as $\mathrm{Ti} / \mathrm{TiN}$ ) under various normal loads. The wear scars were examined by laser confocal scanning microscopy (LCSM), scanning electron microscopy (SEM) and energy dispersive spectroscopy (EDS). The fretting behavior and wear mechanism of the Ti/TiN multilayer film are discussed.

\section{Experimental Details}

\subsection{Preparation of the Samples}

The uranium samples used in this study were abraded, mechanically polished, degreased with acetone and ethanol in an ultrasonic bath, and subsequently dried at room temperature. The sputtering of the Ti/TiN multilayer film was carried out on an ion-plating equipment. The target was high purity $\mathrm{Ti}(99.99 \%)$. The samples were fixed on a continuously rotating planetary holder inside the vacuum chamber. When the base pressure of the vacuum chamber was larger than $5 \times 10^{-4} \mathrm{~Pa}$, the samples were further cleaned by argon ion bombardment for $10 \mathrm{~min}$. After pre-sputtering, a Ti interlayer with thickness of about $50 \mathrm{~nm}$ was firstly deposited on the uranium substrates to enhance the adhesion strength of the coating. The working pressure was kept at $0.3 \mathrm{~Pa}$. Different $\mathrm{N}_{2}$ flows were employed to obtain the Ti/TiN multilayer film. For the Ti layer, argon (99.999\%) was introduced into the chamber with a flow of $40 \mathrm{sccm}$. For the TiN layer, argon (99.999\%) and nitrogen (99.999\%) were introduced into the chamber with a flow of 10 and $40 \mathrm{sccm}$, respectively. The alternative deposition of Ti and TiN layers was repeated to obtain the Ti/TiN multilayer film. The deposition time of Ti and TiN was $5 \mathrm{~min}$ and $10 \mathrm{~min}$ for each layer, respectively. The total deposition time was $1 \mathrm{~h}$.

\subsection{Film Characterization}

The surface morphologies after fretting wear were examined by scanning electric microscopy (SEM, FEI, Hillsboro, OR, USA). The chemical composition and the elements valence of the Ti/TiN multi-layer film were analyzed by X-ray photoelectron spectroscopy (XPS, Thermo Scientific, Waltham, MA, USA) using the Ka line of the Mg X-ray source $(\mathrm{hv}=1253.6 \mathrm{eV})$. The $\mathrm{X}$-ray gun was $15 \mathrm{kV}$. The XPS patters were calibrated using C 1 s line set at $284.8 \mathrm{eV}$.

\subsection{Fretting Tests}

The fretting tests were carried out on an MFT-6000 machine (CETR, Campbell, CA, USA). A pin-on-disc configuration was employed (Figure 1). The counter-body was a GCr15 ball with the diameter of $12 \mathrm{~mm}$. During the test, the instantaneous displacement and the normal force was monitored and recorded for every cycle. The experimental parameters selected were: displacement amplitude of $20 \mu \mathrm{m}$, frequency of $10 \mathrm{~Hz}$, and normal load of 10, 20, 50, and $100 \mathrm{~N}$. The number of cycles was $1 \times 10^{4}$. The fretting tests were conducted in dry conditions at an ambient temperature 
of $25{ }^{\circ} \mathrm{C}$ and relative humidity $50 \%$. Prior to the fretting tests, the samples and counter-body were cleaned with acetone and alcohol. After each test, the morphologies of the wear scars were observed by LCSM (OLYMPUS BX50, Tokyo, Japan) and SEM. The profiles of the fretting scars were assessed using surface profilometry. EDS (FEI, Hillsboro, OR, USA) was used for the element analysis of the wear tracks.

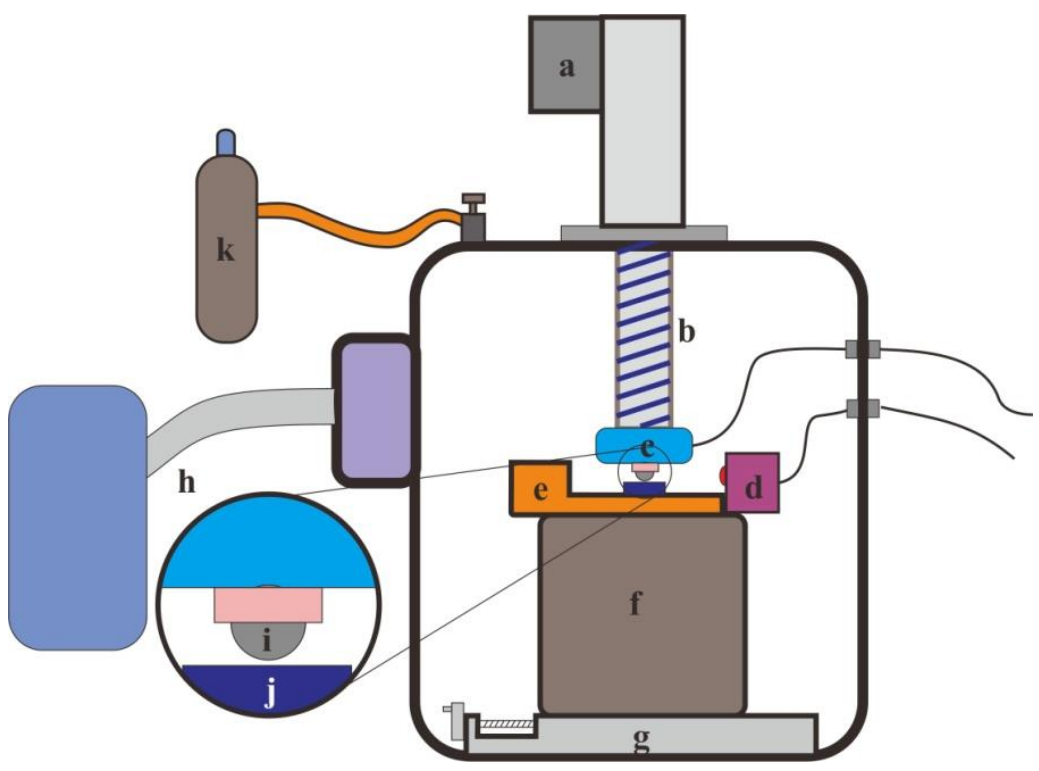

Figure 1. Fretting wear test rig: (a) Servo electric cylinder; (b) Lead screw; (c) Two-dimensional pressure sensor; (d) Laser copolymerization sensor; (e) Piezoelectric ceramics; (f) Base; (g) Screw module; (h) Molecular pump; (i) Counter-body; (j) Sample; (k) Vacuum chamber.

\section{Results and Discussion}

\subsection{Fretting Regions}

The friction loops of uranium for a normal load of 10, 20, 50, and $100 \mathrm{~N}$, under an imposed displacement amplitude of $20 \mu \mathrm{m}$, are shown in Figure 2a-d by blue curves. When the normal load was $10 \mathrm{~N}$ (see Figure 2a), the shapes of the F-D curves were quasi-rectangular, and a relative gross slip took place, which was the typical feature of SR in fretting wear [22,23]. The friction loop increased to a higher friction value with the increase of the fretting wear cycles [24]. When the normal load was up to $50 \mathrm{~N}$ and $100 \mathrm{~N}$ (see Figure 2c,d), the shapes of the F-D curves appeared as elliptical loops in all test cycles. The friction loop shape almost remained the same with the increase of the fretting wear cycles to $10^{4}$ cycles. This was shown by the flat friction coefficients. Therefore, the fretting processes had run in PSR [21,22]. When the normal load was $20 \mathrm{~N}$, the shapes of the F-D curves were composed of an elliptical loop and a quasi-rectangular loop. A partial slip cycle and a gross slip cycle occurred in the same process. Therefore, the fretting process had run in MFR [22,23].

The friction loops of the Ti/TiN multilayer film for a normal load of 10, 20,50, and $100 \mathrm{~N}$ and a displacement amplitude of $20 \mu \mathrm{m}$ are also shown in Figure $2 \mathrm{a}-\mathrm{d}$, indicated by red curves. The F-D curves shape of the Ti/TiN film on uranium changed from parallelogram to ellipse when the normal load increased from 10 to $20 \mathrm{~N}$, indicating that the fretting process also transformed from SR to MFR. When the normal load was $50 \mathrm{~N}$ and $100 \mathrm{~N}$, the shapes of the F-D curves changed to a line in all test cycles. The fretting processes had run in PSR. In short, the transformation trend of the fretting wear behavior of the uranium substrate was in accordance with that of the Ti/TiN multilayer film on $\mathrm{U}$ as the normal load increased. 

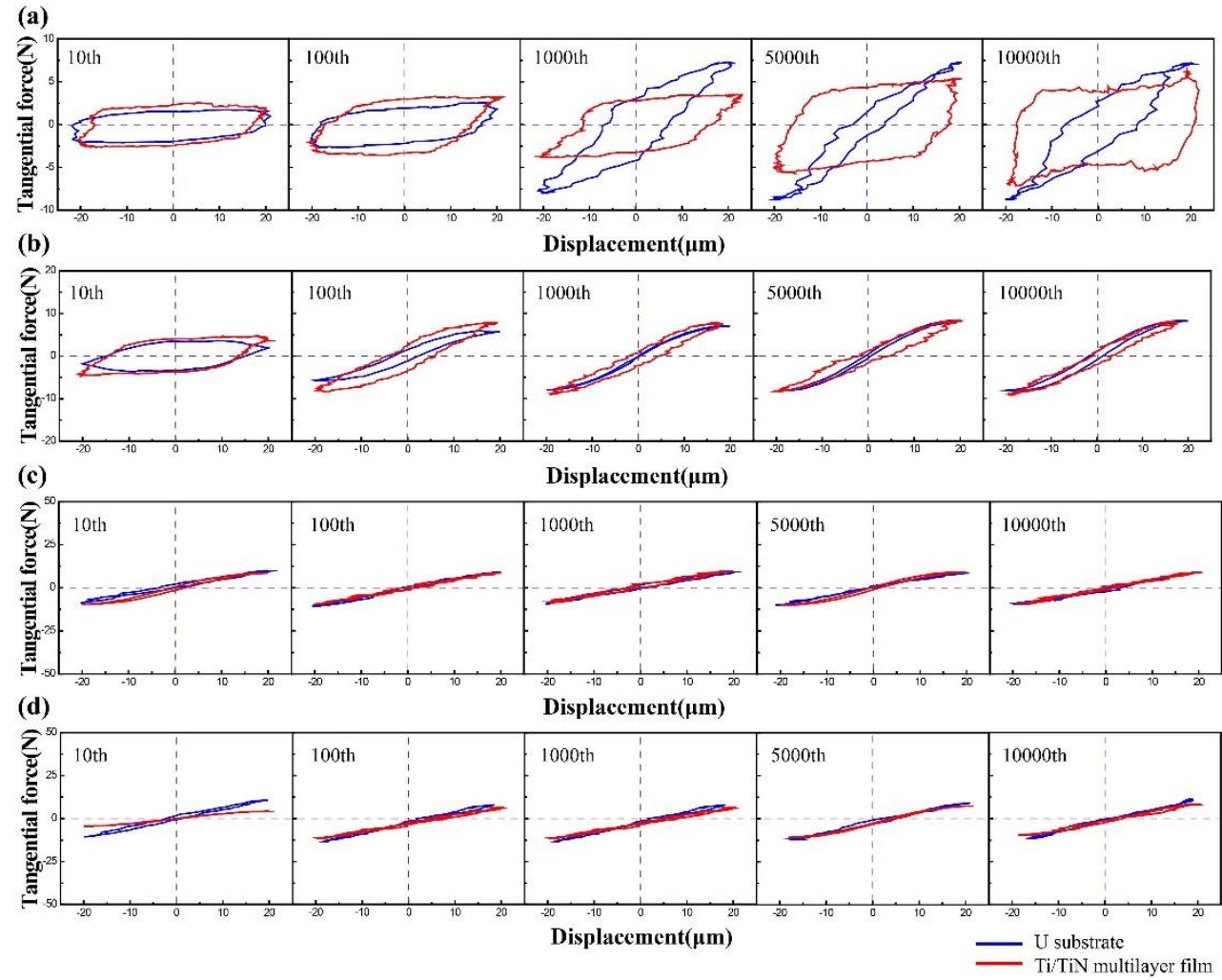

Figure 2. Fretting loops for depleted uranium (DU) and a titanium/titanium nitride (Ti/TiN) film on DU under various normal loads; (a) Fn (force of normal loads) $=10$ N. (b) Fn $=20$ N. (c) Fn $=50$ N. (d) $\mathrm{Fn}=100 \mathrm{~N}$.

\subsection{Friction Coefficient}

Figure 3 exhibits the evolution of the coefficients of friction (COF) for DU and the Ti/TiN multilayer film with the number of cycles at different normal loads. It is obvious that there was a great difference in COF under various normal loads. The COF decreased with the increase of the normal load for both uranium and Ti/TiN multilayer film. The COF increased from 0.1 at the normal load of $100 \mathrm{~N}$ to 0.4 at the normal load of $10 \mathrm{~N}$. The COF was in a steady stage for both uranium and Ti/TiN film in PSR at the normal load of $100 \mathrm{~N}$. The COF of uranium was slightly higher than that of the Ti/TiN film at a high normal load. In the MFR, the COF of the film varied with the cycles. Two stages were observed, including an ascendant stage, corresponding to the COF raising from a lower to a higher level, and a steady stage, characterized by COF values stabilized in a small undulant range, during which an additional third stage causing body wear or a surface roughness change might have occurred. In the SR, the COF of uranium varied with the cycles, and three stages were observed: an initial slowly ascendant stage, a fast ascendant stage, corresponding to the COF raising from a lower to a higher level, and a fluctuant stage, when the COF values descended and ascended repeatedly. The fluctuant stage corresponded to the formation and rejection of debris. 

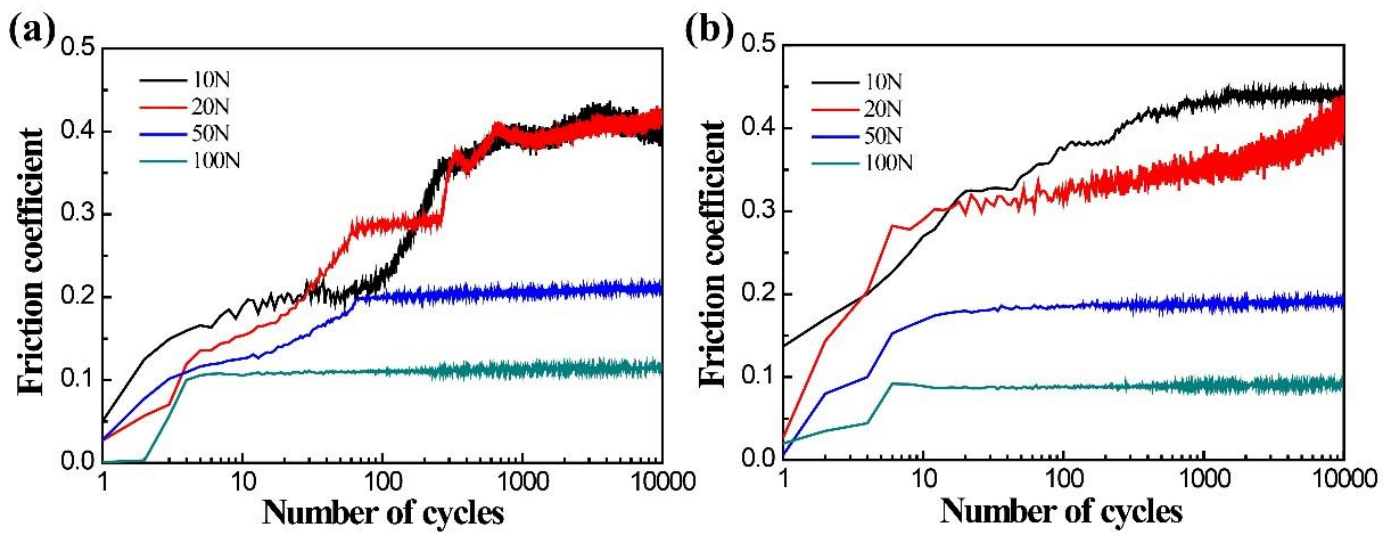

Figure 3. Friction coefficient of DU (a) and Ti/TiN on DU (b) under various normal loads.

\subsection{Fretting Damage and Wear Mechanism}

Figure 4 shows images of the typical wear scars of uranium at normal loads of $10 \mathrm{~N}, 20 \mathrm{~N}$, and $100 \mathrm{~N}$, respectively, and displacement amplitude of $20 \mu \mathrm{m}$. As can be seen from Figure 4, the shapes of the wear scars at the normal loads of $10 \mathrm{~N}$ and $20 \mathrm{~N}$ were nearly elliptic; the shape of the wear scar at the normal load of $100 \mathrm{~N}$ was nearly circular.

In Figure 4a it can be seen that, when the normal load was $10 \mathrm{~N}$, many particles were found on the wear scar. These particles were very small and uniform, which indicated that they had been fully ground in the process of fretting. The particles at the friction interface could easily bind and agglomerate with each other because of their relative motion, resulting in three-body wear and tangential force fluctuation, which was in accordance with the friction coefficient in Figure $3 a$. Meanwhile, some furrows appeared in the center of the friction interface. A thick wear debris layer covered the contact zones. From the F-D curves, the fretting wear process was in SR, so the main wear mechanisms were delamination and abrasive wear in the SR. When the normal load increased to $20 \mathrm{~N}$, the fretting wear ran in the MFR. A few detached particles covered the contact zone and formed third-body contact. Wear scars were relatively rough with obvious plastic deformation. The center of the wear scars was adhesive, and the edge of the wear scar had a slight sliding area. Lamellate plates were also present in the fretting scars (Figure $4 \mathrm{~b}$ ). Delamination was the main wear mechanism in the MFR. When the normal load was $100 \mathrm{~N}$, only small scratches were observed on the fretting wear area of uranium (Figure 4c). No damage was observed at the contact center. Slight scratches appeared on the contact edge, but there were no wear debris on the wear scar.

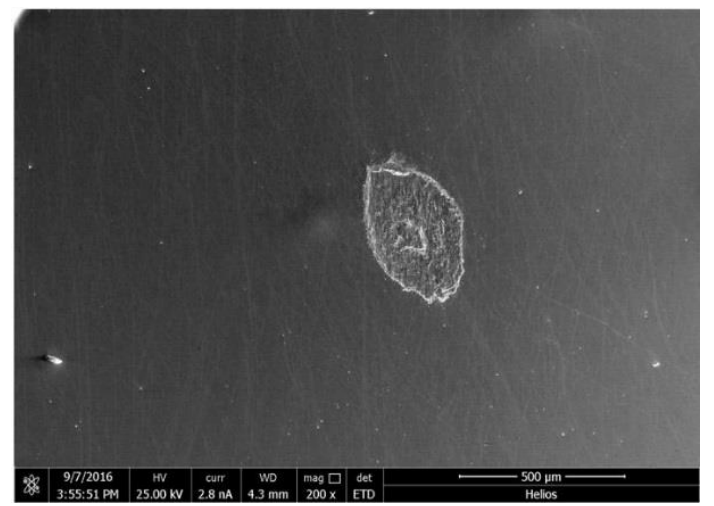

(a)

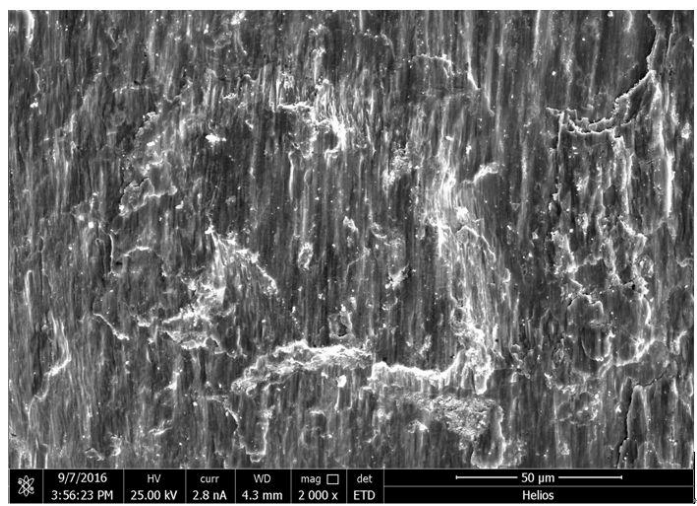

(b)

Figure 4. Cont. 


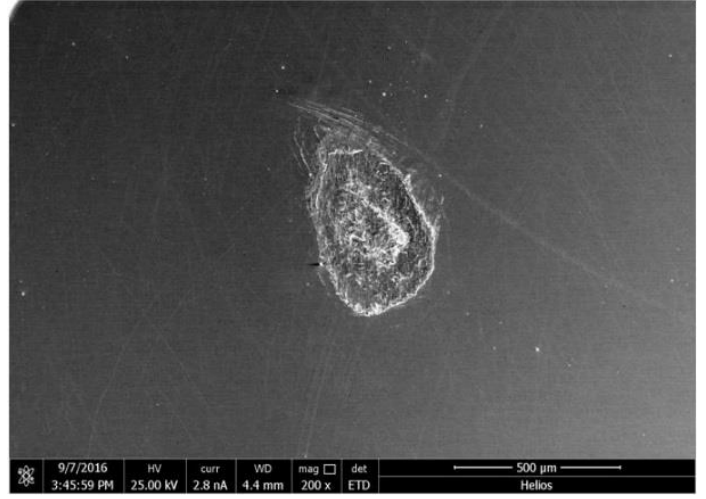

(c)

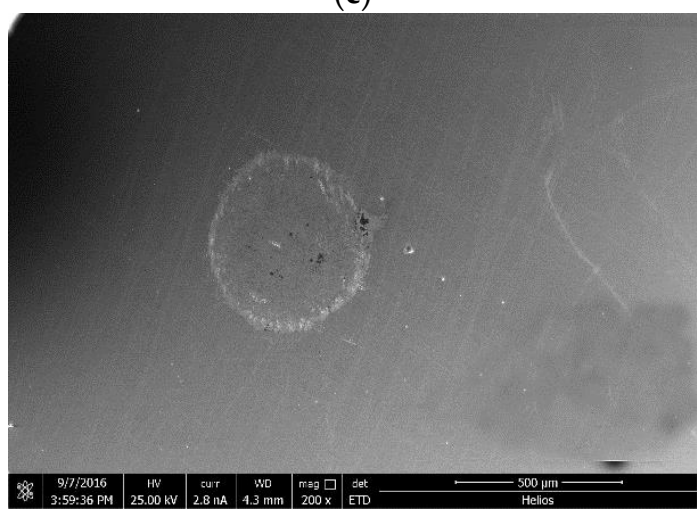

(e)

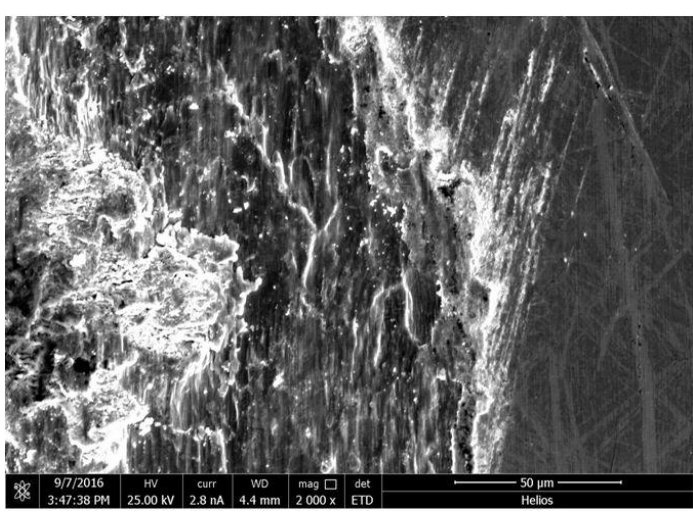

(d)

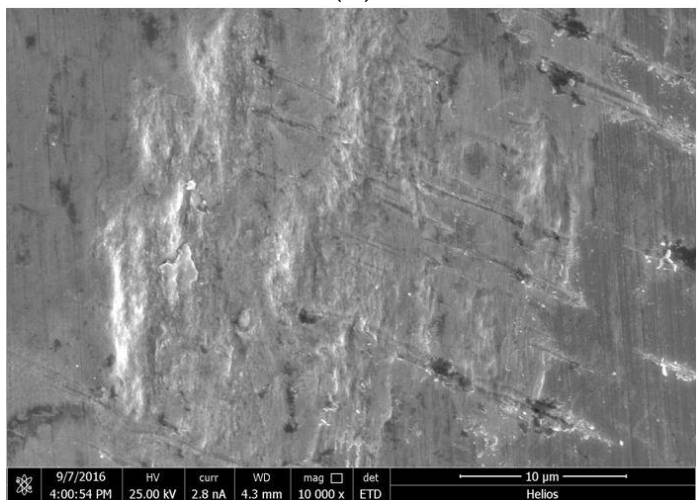

(f)

Figure 4. SEM morphologies of the fretting damages on a uranium surface under normal loads of $10 \mathrm{~N}$ $(\mathbf{a}, \mathbf{b}), 20 \mathrm{~N}(\mathbf{c}, \mathbf{d}), 100 \mathrm{~N}(\mathbf{e}, \mathbf{f})$.

The 3D wear profiles of the Ti/TiN multilayer film on uranium are shown in the Figure 5 . It can be seen that, at the loads of 10 and $20 \mathrm{~N}$, the wear debris were not discharged completely during the test, so the wear scars were partly bulgy. When the load increased to $100 \mathrm{~N}$, there was just a slightly indentation on the wear surface. The morphology of the contact center was almost unchanged, only the wear edge presented a slightly orbicular damage.

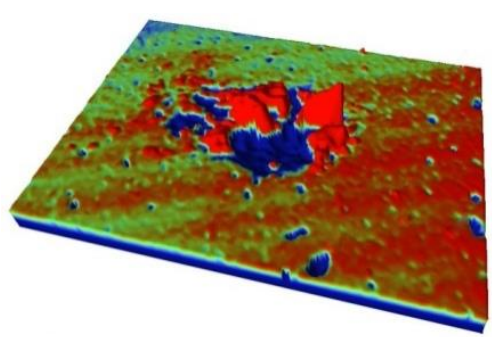

(a)

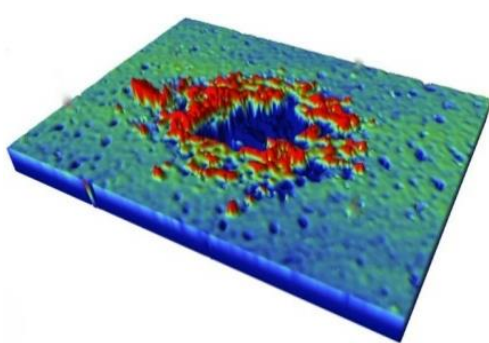

(b)

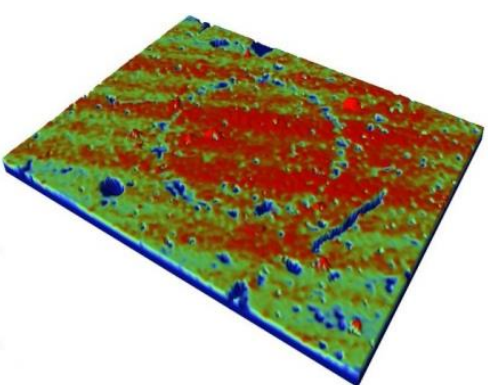

(c)

Figure 5. 3D profile of the Ti/TiN multilayer film on DU at different normal loads; (a) $10 \mathrm{~N}$, (b) $20 \mathrm{~N}$, (c) $100 \mathrm{~N}$.

Figure 6 shows images of the typical wear scars on the Ti/TiN multilayer film for a displacement amplitude of $20 \mu \mathrm{m}$ and normal loads of 10, 20 and $100 \mathrm{~N}$, respectively. From Figure 6a, when the normal load was $10 \mathrm{~N}$, a thick debris layer covered the contact zones, which indicated the wear mechanism was abrasive wear. The wear scars were full of grooves and detached debris, differently 
from what reported by TiN Zhou [25], who found many fine particles on the wear scars due to the brittle of the TiN film. The reason for this discrepancy is that the soft Ti layer improved the toughness of the $\mathrm{Ti} / \mathrm{TiN}$ multilayer film, and the layered structure damage clearly appeared at the wear scar because of the different hardness and elasticity modulus of the multi-layer structure. Table 1 shows the element analysis of the wear tracks. In spot 1, the elements were mainly $\mathrm{Ti}$ and $\mathrm{O}$ with a little of $\mathrm{Fe}$ and $\mathrm{Cr}$ (mainly coming from the counter-body), which indicated that the detached Ti/TiN debris could be oxides in the process of fretting wear with a normal load of $10 \mathrm{~N}$. In spot 2, the dominant elements were mainly $\mathrm{Ti}$ and $\mathrm{N}$ from the Ti/TiN multi-layer film. The Ti/TiN multilayer film was degraded as a result of gross sliding. The wear debris on the wear scars of the Ti/TiN multilayer film were significantly fewer than those on uranium. Delamination and oxidation were the main wear mechanisms of the Ti/TiN multilayer film in the SR.

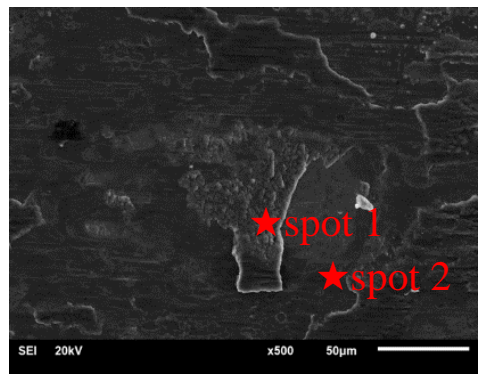

(a)

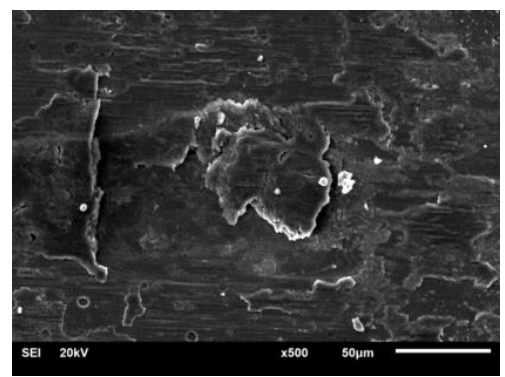

(b)

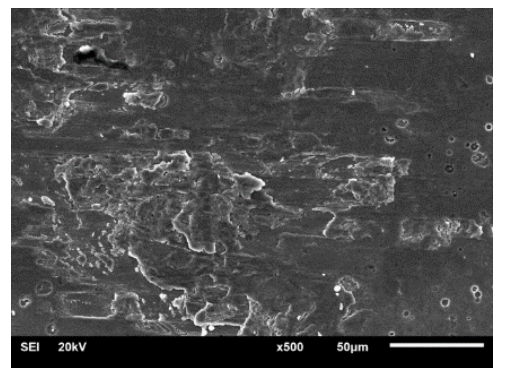

(c)

Figure 6. SEM morphologies of the fretting damages on the Ti/TiN multilayer film deposited on uranium under normal loads of $10 \mathrm{~N}(\mathbf{a}), 20 \mathrm{~N}(\mathbf{b}), 100 \mathrm{~N}$ (c).

Table 1. Energy dispersive spectroscopy (EDS) analysis results in spots 1 and 2, as indicated in Figure 6a.

\begin{tabular}{ccc}
\hline Element & Spot 1 Atomic \% & Spot 2 Atomic \% \\
\hline O K & 75.62 & - \\
N K & - & 45.00 \\
Ti K & 22.43 & 47.75 \\
Cr K & 0.17 & 0.77 \\
Fe K & 1.79 & 6.48 \\
\hline
\end{tabular}

When the normal load was $20 \mathrm{~N}$, the fretting wear ran in the MFR. Lamellate plates also appeared in the fretting scars. Layered structure damage and few wear debris occurred on the wear scars. The substrate material did not emerge on the surface, which indicated that the multilayer film was not worn out. From the EDS spectra [26], at the center of the wear scars, the dominant elements were Ti and $\mathrm{N}$, with a low content of $\mathrm{O}$ and Fe. At the edge of the wear scar, the content of Fe and $\mathrm{O}$ increased with the decrease of the content of $\mathrm{Ti}$ and $\mathrm{N}$. Ti and $\mathrm{N}$ appeared in a "W" shape, indicating that the $\mathrm{Ti} / \mathrm{TiN}$ multilayer film wear was much more severe at the edges than in the center. Delamination was the main wear mechanism of the Ti/TiN multilayer film in the MFR.

It was observed that the $\mathrm{Ti} / \mathrm{TiN}$ multilayer film had a strong plastic deformation when the normal load was $100 \mathrm{~N}$ (Figure 6c). Small damage was observed at the contact center. Lamellate plates appeared in the fretting scars. However, the area of delamination was lower than that at $10 \mathrm{~N}$, and each delamination was adhesive. Only a few wear debris appeared on the wear scar. The reason might be that the fretting ran in the PSR and underwent plastic deformation when the load was $100 \mathrm{~N}$.

The XPS Ti2p spectra of the Ti/TiN multilayer film at $20 \mathrm{~N}$ and $100 \mathrm{~N}$ are shown in Figure 7. In the figure of the XPS Ti2p spectra at $20 \mathrm{~N}$, the peaks at $458.6 \mathrm{eV}$ and $464.3 \mathrm{eV}$ belong to $\mathrm{TiO}_{2}$ and are Ti2p3/2 and Ti2p1/2, respectively. In contrast, the XPS Ti2p spectra at $100 \mathrm{~N}$ comprise three Ti2p3/2 doublet peaks at 455.2, 456.1, and $458.5 \mathrm{eV}$, which were assigned to TiN, Ti-O-N, and $\mathrm{TiO}_{2}$. 
It can be seen that the TiN and Ti-O-N peaks appeared at $100 \mathrm{~N}$, because small damage and limited oxidation occurred in the wear scar, partly destroying the Ti/TiN multilayer film. However, at $20 \mathrm{~N}$, the oxidation reaction was severe and the film was oxidized to $\mathrm{TiO}_{2}$; therefore, no TiN and $\mathrm{Ti}-\mathrm{O}-\mathrm{N}$ appeared in the wear scar that presented a serious fretting damage.

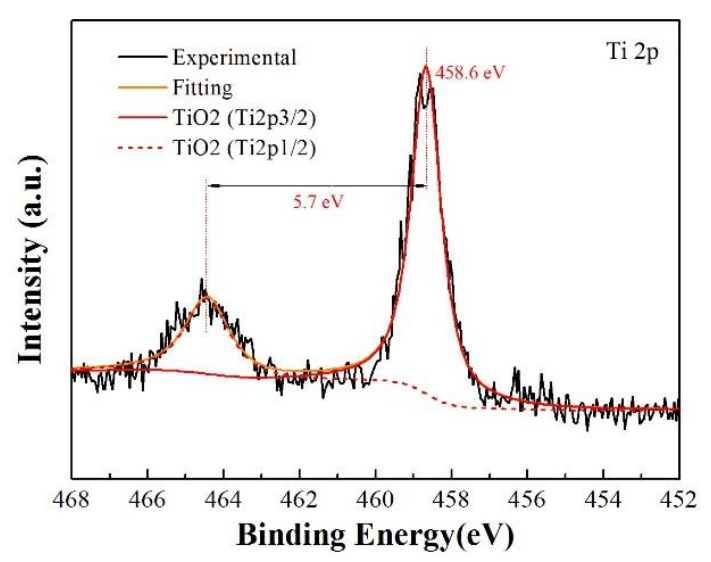

(a)

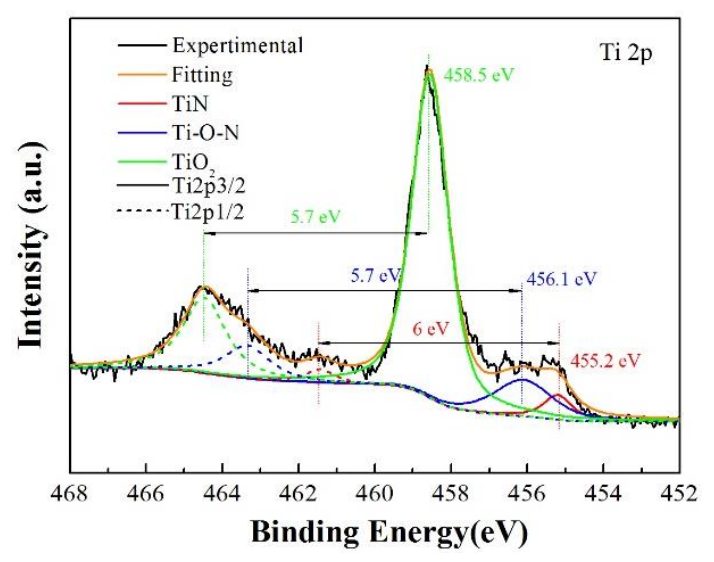

(b)

Figure 7. Photoelectron spectroscopy (XPS) Ti2p spectra of the Ti/TiN multilayer film at different normal loads; (a) $20 \mathrm{~N}$, (b) $100 \mathrm{~N}$.

The XPS N 1s spectra of the Ti/TiN multilayer film at $20 \mathrm{~N}$ and $100 \mathrm{~N}$ are shown in Figure 8. From the spectra at $20 \mathrm{~N}$, it can be seen that the TiN peak is very weak and no other peak is visible in the spectra. In the spectra at $100 \mathrm{~N}$, the TiN and Ti-O-N peaks can be seen clearly, which indicates that the wear scar was composed of $\mathrm{TiO}_{2}, \mathrm{Ti}-\mathrm{O}-\mathrm{N}$, and TiN. The analysis results of $\mathrm{N} 1 \mathrm{~s}$ were in accordance with the results of Ti $2 p$.

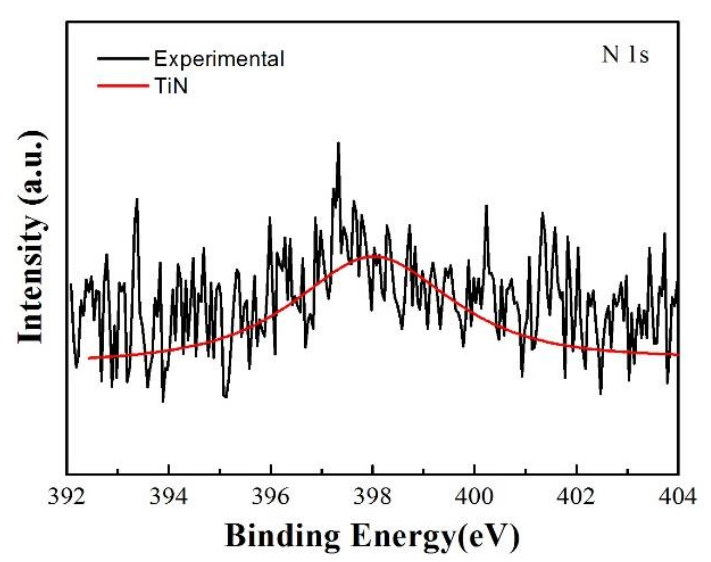

(a)

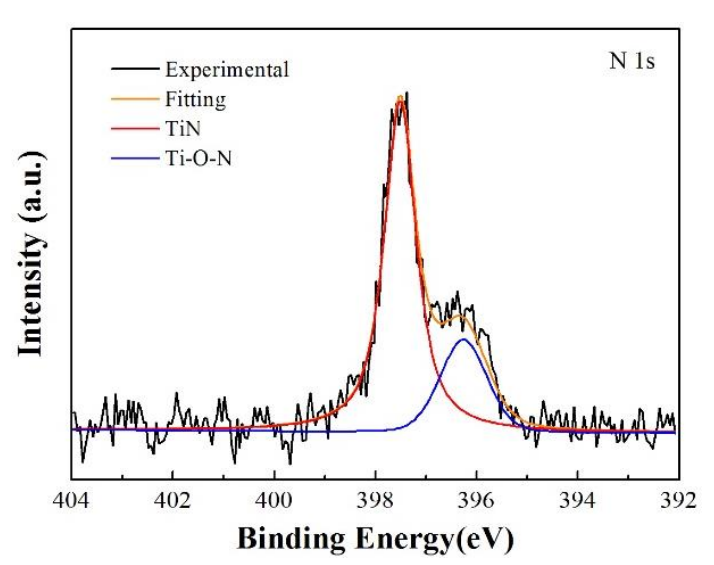

(b)

Figure 8. XPS N 1s spectra of the Ti/TiN multilayer film at different normal loads; (a) 20 N, (b) 100 N.

\subsection{Scar Profiles and Wear Rates}

The scar profiles were taken along the center line using a profilometer. Figure 9 presents the scar profiles of uranium and the Ti/TiN multi-layer film for various normal loads. In Figure 9, it can be seen that when the normal load was $10 \mathrm{~N}$, the scar presented a "U" shape, typical of a wear scar in SR; when the normal load was $20 \mathrm{~N}$, the scar presented a "W" shape, typical of a wear scar in MFR; the profiles at a high normal load showed a very slight material transfer, which appeared on the counter-body. 
Figure 9 shows that the wear depth was larger than the film thickness, when the normal loads were 10 and $20 \mathrm{~N}$. The film was completely removed in the wear scars. At the normal load of 50 and $100 \mathrm{~N}$, the depth of the wear scars in the center was smaller than the film thickness. The film was incompletely removed from the contact zone, although some scratch formed. The protective effect of the film was maintained after $10^{4}$ cycles.

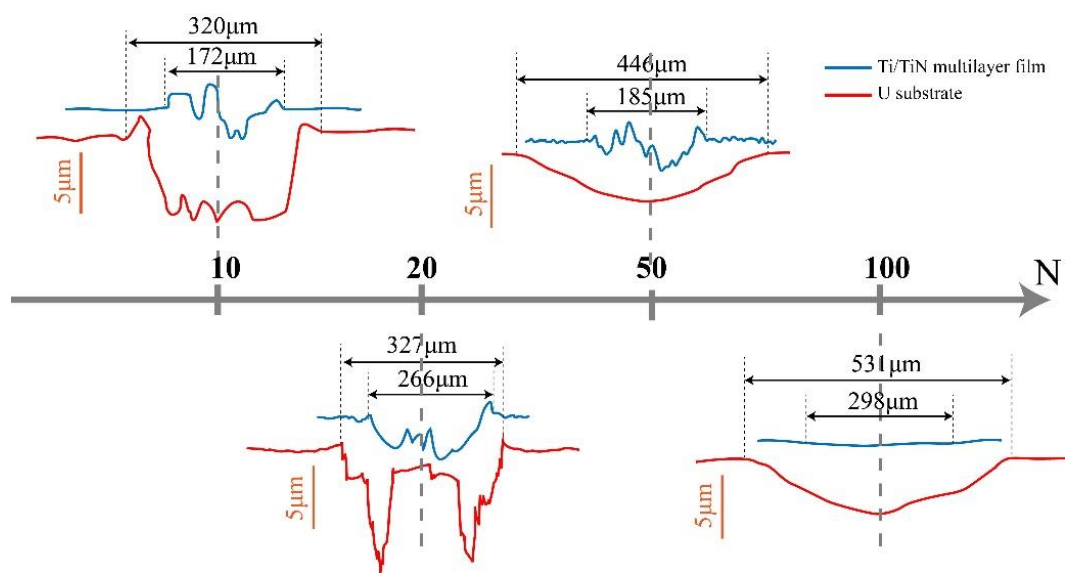

Figure 9. Wear profiles of uranium and the Ti/TiN multilayer film at different normal loads.

The wear depth of the Ti/TiN multilayer film was only of one-tenth of that of uranium, which showed that the $\mathrm{Ti} / \mathrm{TiN}$ multilayer film improved the wear resistance of uranium.

The wear volumes and wear rates of uranium and the Ti/TiN multilayer film are shown in Figure 10. The wear volume is the amount of material removed from the surface during sliding. The wear rate $(R)$ can be calculated using the following equation [11]:

$$
R=V /(F n \cdot D)
$$

where $V$ is the wear volume $\left(\mathrm{mm}^{3}\right), F n$ is the normal force applied $(\mathrm{N})$, and $D$ is the sliding distance $(\mathrm{m})$.

The wear volume of uranium was irregular, and the maximum wear volume was recorded at the load of $20 \mathrm{~N}$, corresponding to $6.2 \times 10^{5} \mu \mathrm{m}^{3}$. However, the wear volume of the Ti/TiN multilayer film firstly increased and then decreased. This phenomenon was related to the fretting region. From Figure 10b, the wear rates of uranium and the Ti/TiN multilayer film decreased with the load. In generally, the Ti/TiN multilayer film could greatly improve the fretting wear properties of uranium.

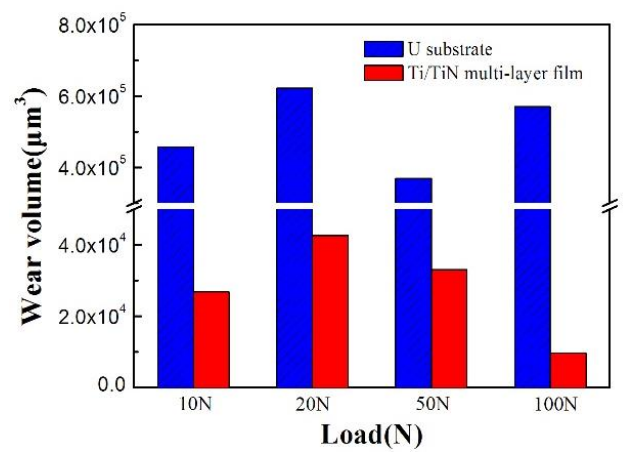

(a)

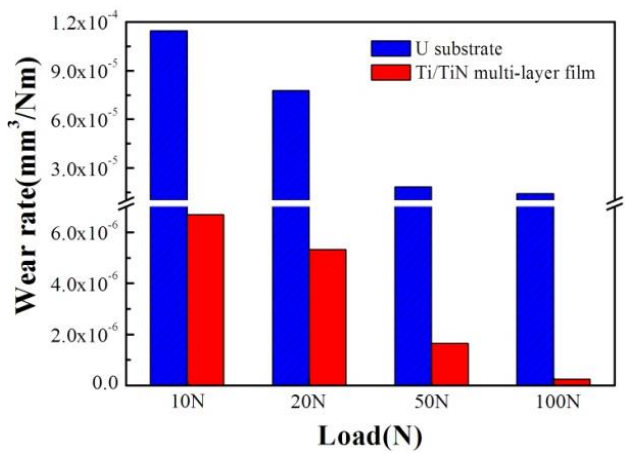

(b)

Figure 10. Wear volume and wear rate of uranium and the $\mathrm{Ti} / \mathrm{TiN}$ film at different normal loads. (a) wear volume, (b)wear rate. 


\section{Conclusions}

The fretting behavior of a Ti/TiN multilayer film deposited on the surface of a uranium sample was investigated under different normal loads, using a pin-on-disc configuration. The coefficients of friction differed greatly under various normal loads. The friction coefficients decreased with the increase of the normal load for both uranium and Ti/TiN multilayer film. For uranium, delamination and abrasion were the main wear behaviors under different normal loads. In contrast, for the Ti/TiN multilayer film on uranium, delamination and oxidation were the dominant wear behaviors. The XPS analysis results also showed that the $\mathrm{Ti} / \mathrm{TiN}$ coatings were oxidized and formed $\mathrm{TiO}_{2}$ during fretting wear. The wear depth of the uranium substrate was much greater than that of the Ti/TiN multilayer film at the same normal loads, which showed that the Ti/TiN multilayer film could effectively improve the wear properties of depleted uranium.

Author Contributions: S.Z., Y.W. and Z.L. did the experiments and wrote the paper. L.F. and J.Y. contributed to the supervision of research, checked and polished the manuscript, F.J., A.Y. and X.M. contributed materials/analysis tools and performed the experiments; Z.C., Y.W. and P.C. provided the original ideas and designed the experiments.

Funding: This research was funded by the NSAF (U1530136), National Science Foundation of China (11505159 and 11702261), the Young Scientific Innovation Team of Science and Technology of Sichuan (2017TD0017), the Discipline Development Foundation of China Academy of Engineering Physics (2015B0301065), and the Foundation of Science and Technology on Surface Physics and Chemistry Laboratory (WDZC201801).

Acknowledgments: The authors would like to thank Minhao Zhu for useful advice.

Conflicts of Interest: The authors declare no conflict of interest.

\section{References}

1. Bai, B.; Xiao, Y.; Lang, D.; Liu, Q. Friction Characteristics of Plasma-Sprayed Sn and $\mathrm{ZrO}_{2}$ Coatings against U-Nb Alloy. Rare Met. Mater. Eng. 2005, 34, 1114-1118.

2. Li, Z.; Cai, Z.; Wu, Y. Fretting Wear Damage Mechanism of Uranium under Various Atmosphere and Vacuum Conditions. Materials 2018, 11, 607. [CrossRef] [PubMed]

3. Zhou, Z.R. Recent development in fretting research. Tribology 1997, 17, 272-280.

4. Hager, C.H.; Sanders, J.H.; Sharma, S. Unlubricated gross slip fretting wear of metallic plasma-sprayed coatings for Ti6Al4V. Wear 2008, 265, 439-451. [CrossRef]

5. Roeper, D.F.; Chidambaram, D.; Clayton, C.R.; Halada, G.P. Development of an Environmental Friendly Protective Coating for the Depleted Uranium- $0.75 \mathrm{wt} \%$ Titanium Alloy: Part V. Electrochemical impedance spectroscopy of the coating. Electrochim. Acta 2008, 53, 2130-2134. [CrossRef]

6. Roeper, D.F.; Chidambaram, D.; Clayton, C.R.; Halada, G.P. Development of an Environmental Friendly Protective Coating for the Depleted Uranium- $0.75 \mathrm{wt} \%$ Titanium Alloy: Part I. Surface Morphology and Electrochemistry. Electrochim. Acta 2005, 50, 3622-3633. [CrossRef]

7. Haschke, J.M. Corrosion of Uranium in Air and Water Vapor: Consequences for Environmental Dispersal. J. Alloys Compd. 1998, 278, 149-160. [CrossRef]

8. Liang, H.; Bu, Y.; Zhang, J.; Cao, Z.; Liang, A. Graphene Oxide Film as Solid Lubricant. ACS Appl. Mater. Interfaces 2013, 5, 6369-6375. [CrossRef] [PubMed]

9. Rui, H.; Aleksander, A.T.; David, J.L.; Chris, P.W.; Kevin, R.W.; Philip, H.; Sander, G.; Shen, J.D.; Paul, B. Property Self-Optimization During Wear of $\mathrm{MoS}_{2}$. ACS Appl. Mater. Interfaces 2017, 9, 1953-1958.

10. Khetan, V.; Valle, N.; Duday, D.; Michotte, C.; Mitterer, C.; Delplancke, M.P.; Choquet, P. Temperature Dependent Wear Mechanisms for Magnetron-Sputtered AlTiTaN Hard Coatings. ACS Appl. Mater. Interfaces 2014, 6, 15403-15411. [CrossRef] [PubMed]

11. Oleksiy, V.P.; Alexander, Y.D.; Mahdi, K.; Evgeniy, N.Z.; Valeriy, V.K.; DaeEun, K. Toward Zero Micro/Macro-Scale Wear Using Periodic Nano-Layered Coatings. ACS Appl. Mater. Interfaces 2015, 7, 18136-18144.

12. Wu, P.Q.; Chen, H.; Stappen, M.V.; Stals, L.; Celis, J.P. Comparision of fretting wear of uncoated and PVD TiN coated high-speed steel under different testing conditions. Surf. Coat. Technol. 2000, 127, 114-119. [CrossRef]

13. Gu, B.L.; Liu, H.W.; Zhu, M.H.; Zhang, P.C.; Zhou, Z.R. Fretting wear behavior of TiN/Ti composites formed at elevated temperature. Surf. Eng. 2010, 23, 89-94. 
14. Zalnezhad, E.; Sarhan, A.A.D.; Hamdi, M. Investigating the fretting fatigue life of thin film titanium nitride coated aerospace Al7075-T6 alloy. Mater. Sci. Eng. A 2013, 559, 436-446. [CrossRef]

15. Maab, S.; Procházka, J.; Karvánkov, P. Comparative study of the tribological behaviour of superhard nano-composite coatings nc-TiN/a-Si3N4 with TiN. Surf. Coat. Technol. 2005, 194, 143-148.

16. Polcar, T.; Kubart, T.; Novák, R. Comparison of tribological behaviour of TiN, TiCN and CrN at elevated temperatures. Surf. Coat. Technol. 2005, 193, 192-199. [CrossRef]

17. Chen, G.X.; Zhou, Z.R. Study on transition between fretting and reciprocating sliding wear. Wear 2001, 250, 665-672. [CrossRef]

18. Zhang, X.H.; Liu, D.X.; Tan, H.B.; Wang, X.F. Effect of TiN/Ti composite coating and shot peening on fretting fatigue behavior of TC17 alloy at $350^{\circ} \mathrm{C}$. Surf. Coat. Technol. 2009, 203, 2315-2321. [CrossRef]

19. Rybiak, R.; Fouvry, S.; Liskiewicz, T.; Wendler, B. Fretting wear of a TiN PVD coating under variable relative humidity conditions-development of a 'composite' wear law. Surf. Coat. Technol. 2008, 202, 1753-1763. [CrossRef]

20. Hendry, J.A.; Pilliar, R.M. The fretting corrosion resistance of PVD surface-modified orthopedic implant alloys. J. Biomed. Mater. Res. 2001, 58, 156-166. [CrossRef]

21. Zhang, X.H.; Liu, D.X. Effect of TiN/Ti multilayer on fretting fatigue resistance of Ti-811 alloy at elevated temperature. Trans. Nonferr. Met. Soc. China 2009, 19, 557-562. [CrossRef]

22. Zhou, Z.R.; Vincent, L. Mixed fretting region. Wear 1995, 181-183, 531-536. [CrossRef]

23. Zhu, M.H.; Cai, Z.B.; Lin, X.Z.; Ren, P.D.; Tan, J.; Zhou, Z.R. Fretting wear behaviour of ceramic coating prepared by micro-arc oxidation on Al-Si alloy. Wear 2007, 263, 472-480. [CrossRef]

24. Tang, Z.Q.; Talke, F.E. Fretting wear volume and wear coefficient at the dimple/gimbal interface of a hard disk drive suspension. Microsyst. Technol. 2015, 21, 2533-2538. [CrossRef]

25. Xu, G.Z.; Zhou, Z.R.; Liu, J.J. A comparative study on fretting wear-resistant properties of ion-plated TiN and magnetron-sputtered $\mathrm{MoS}_{2}$ coatings. Wear 1999, 224, 211-215. [CrossRef]

26. Wu, Y.P.; Li, Z.Y.; Zhu, S.F.; Lu, L.; Cai, Z.B. Effect of frequency on fretting wear behavior of Ti/TiN multilayer film on depleted uranium. PLoS ONE 2017, 12, e0175084. [CrossRef] [PubMed]

(C) 2018 by the authors. Licensee MDPI, Basel, Switzerland. This article is an open access article distributed under the terms and conditions of the Creative Commons Attribution (CC BY) license (http:/ / creativecommons.org/licenses/by/4.0/). 